\title{
Pengaruh Motivasi dan Disiplin terhadap Kinerja Karyawan PT. Polypet Indonesia di Jakarta
}

\author{
Nurul Ilham \\ Universitas Pamulang, Tangerang Selatan, Banten, Indonesia \\ E-mail: dosen02548@unpam.ac.id
}

\begin{abstract}
Article Info
Abstract

Article History

Received: 2021-07-12

Revised: 2021-08-15

Published: 2021-09-13

This study aims to determine the effect of motivation and discipline on employee performance at PT. Indonesian Polypet in Jakarta. The method used is explanatory research with analytical techniques using statistical analysis with regression, correlation, determination and hypothesis testing. The results of this study that

Keywords:

Motivation;

Discipline;

Employee performance. motivation has a significant effect on employee performance by $45.0 \%$, hypothesis testing is obtained $t$ count $>t$ table or $(7.062>2,000)$. Discipline has a significant effect on employee performance by $50.8 \%$, hypothesis testing is obtained $t$ count $>t$ table or $(7,942>2,000)$. Motivation and discipline simultaneously have a significant effect on employee performance with the regression equation $\mathrm{Y}=5.789+0.368 \mathrm{X} 1+0.501 \mathrm{X} 2$. The contribution of influence is $63.6 \%$, hypothesis testing is obtained by $\mathrm{F}$ arithmetic > F table or $(18.770>2.760)$.
\end{abstract}

\begin{tabular}{ll}
\hline Artikel Info & Abstrak \\
\hline Sejarah Artikel & Penelitian ini bertujuan untuk mengetahui pengaruh motivasi dan disiplin terhadap \\
Diterima: 2021-07-12 & kinerja karyawan pada PT. Polypet Indonesia di Jakarta. Metode yang digunakan \\
Direvisi: 2021-08-15 & adalah explanatory research dengan teknik analisis menggunakan analisis statistik \\
Dipublikasi: 2021-09-13 & $\begin{array}{l}\text { dengan pengujian regresi, korelasi, determinasi dan uji hipotesis. Hasil penelitian ini } \\
\text { motivasi berpengaruh signifikan terhadap kinerja karyawan sebesar 45,0\%, uji }\end{array}$ \\
Kata kunci: & hipotesis diperoleh t hitung $>$ t tabel atau $(7,062>2,000)$. Disiplin berpengaruh \\
Motivasi; & signifikan terhadap kinerja karyawan sebesar 50,8\%, uji hipotesis diperoleh t hitung $>$ \\
Disiplin; & t tabel atau (7,942 > 2,000). Motivasi dan disiplin secara simultan berpengaruh \\
Kinerja Karyawan. & signifikan terhadap kinerja karyawan dengan persamaan regresi Y $=5,789+0,368 X 1+$ \\
& 0,501X2. Kontribusi pengaruh sebesar 63,6\%, uji hipotesis diperoleh F hitung $>$ F tabel \\
& atau $(18,770>2,760)$.
\end{tabular}

\section{PENDAHULUAN}

Perusahaan merupakan suatu organisasi yang mempunyai berbagai macam tujuan, aktivitas suatu perusahaan dalam pencapaian tujuan tersebut diperlukan pengelolaan faktorfaktor produksi yang terdiri dari sumber daya alam, sumber daya manusia, modal, bahan baku, mesin, teknologi, perusahaan harus selalu memperhatikan keterkaitan antara faktor-faktor produksi tersebut, dengan demikian perusahaan dituntut untuk dapat mengelola dengan sebaik-baiknya terutama dalam bidang sumber daya manusia sehingga mampu bekerja lebih efektif dan efisien.

Sumber daya manusia yang merupakan salah satu faktor yang ikut terlibat secara langsung dalam menjalankan kegiatan perusahaan dan berperang penting dalam meningkatkan produktivitas perusahaan dalam mencapai tujuan yang telah ditetapkan, sumber daya manusia dituntut untuk mampu mengatasi segala tantangan dan diharapkan mampu memanfaatkan peluang serta dapat memenuhi tuntutan kebutuhan, khususnya yang ada atau atang dari lingkungan kerjanya.

PT. Polypet Indonesia sebagai salah satu pelaku usaha manufacturer di industri dibidang biji plastik dimana pasarnya di eksport ke beberapa Negara, dengan telah diberlakukannya perdagangan bebas semua pelaku bisnis tidak terkecuali PT. Polypet Indonesia terus memperkuat pangsa pasar dalam negeri sebagai salah satu langkah menghadapi persaingan global dan ikut memperkuat pertumbuhan industri dalam negeri, maka PT. Polypet Indonesia bertekad untuk menjadi perusahaan yang konsisten dengan menjaga kualitas sumber daya manusianya sehingga semua aspek yang diperlukan dapat menunjang kinerja dapat dicapai dengan maksimal, guna menyelaraskan visi dan misi, PT. Polypet Indonesiaharus terus berusaha memperbaiki kemampuan sumber daya manusia sehingga mampu mewujudkan 
tujuan perusahaan dengan baik.

Motivasi menjadi salah satu faktor penting bagi perusahaan, demi tercapainya tujuan organisasi, karyawan bagian assembling memerlukan motivasi untuk bekerja lebih rajin, melihat pentingnya karyawan dalam organisasi, maka karyawan diperlukan perhatian lebih serius terhadap tugas yang dikerjakan sehingga tujuan organisasi tercapai. Dengan motivasi kerja yang tinggi, karyawan akan bekerja lebih giat didalam melaksanakan pekerjaannya. Sebaliknya dengan motivasi kerja yang rendah karyawan tidak mempunyai semangat bekerja, mudah menyerah, dan kesulitan dalam menyelesaikan pekerjaannya.

Motivasi akan muncul apabila manusia sudah merasa dipenuhi segala kebutuhannya, oleh karena itu apabila kebutuhannya tidak terpenuhi maka akan menimbulkan permasalahan yang berujung pada beberapa kasus yang seringkali terjadi diperusahaan misalnya pemogokan buruh, tuntutan kenaikanupah dan lain sebagainya, hal ini merupakan pertanda bahwa ada ketidakpuasan yang dirasakan oleh karyawan terhadap perusahaan. Peranan motivasi adalah untuk mengintensifkan hasrat dan keinginan tersebut, oleh karena itu dapat disimpulkan bahwa usaha peningkatan semangat kerja seseorang akan selalu terkait dengan usaha memotivasinya sehingga untuk mengadakan motivasi yang baik perlu mengetahui kebutuhan-kebutuhan manusia.

Menurut Maslow dalam Sutrisno (2017:55), menyatakan bahwa "motivasi merupakan daya penggerak yang menciptakan kegairahan kerja seseorang, agar mereka mau bekerja sama, bekerja efektif dan terintegrasi dengan segala upayanya untuk mencapai kepuasan dalam bekerja", disiplin kerja juga merupakan faktor penting dalam tercapainya tujuan suatu organisasi. Disiplin kerja yang tidak berjalan dengan baik akan berdampak pada kemajuan organisasi. Tanpa disiplin yang baik pada karyawan, sulit bagi organisasi untuk mencapai hasil yang optimal. Tindakan tidak disiplin (Indisipliner) akan berdampak pada pertumbuhan organisasi perusahaan, disiplin dikatakan juga sebagai sarana untuk melatih dan mendidik orang-orang terhadap peraturan- peraturan agar ada kepatuhan dan supaya dapat berjalan dengan tertib dan teratur dalam organisasi. Peraturan perusahaan dibuat tentu bertujuan agar dapat dipatuhi oleh karyawan baik dari ketaatan karyawan dalam menepati waktu bekerja, ketaatan dalam mematuhi semua aturan yang ada dalam perusahaan, ketaatan terkait perilaku karyawan dalam menjalankan tugas dan kewajibannya, ketaatan karyawan dalam menjunjung tinggi norma hukum dan aturanlainnya.

Menegakkan suatu kedisiplinan penting bagi perusahaan, sebab kedisiplinan berisikan peraturan-peraturan yang harus ditaati karyawan, dengan kedisiplinan diharapkan dapat membuat pekerjaan seefisien mungkin. Disiplin kerja dapat dilihat sebagai sesuatu yang besar manfaatnya, baik bagi kepentingan organisasi maupun bagi para karyawan, bagi organisasi adanya disiplin kerja akan menjamin terpeliharanya tata tertib dan kelancaran pelaksanaan tugas, sehingga diperoleh hasil yang optimal. Sedangkan bagi karyawan akan diperoleh suasana kerja yang menyenangkan sehingga akan menambah semangat kerja dalam melaksanakan pekerjaannya.

Karyawan juga harus memiliki rasa tanggung jawab yang tinggi menunjukkan kedisiplinan kita dalam bekerja, seperti mengerjakan tugas- tugas yang diberikan dan menyelesaikannya tepat waktu, pekerja yang disiplin bukan hanya selalu menerima tugas yang diberikan, menyelesaikan tugas dengan sempurna juga merupakan bentuk tanggung jawab terhadap pekerjaan, perusahaan juga penting mensosialisasikan semua ketentuan dan peraturan perusahaan agar dapat dipahami oleh karyawan dan diawasi, dilakukan kontrol dengan baik sehingga tidak terjadi hambatan yang dapat memperlambat tercapainya tujuan perusahaan, dengan demikian, karyawan dapat melaksanakan tugasnya dengan penuh kesadaran serta dapat mengembangkan tenaga dan pikirannya semaksimal mungkin demi terwujudnya tujuan organisasi, kinerja merupakan salah satu komponen yang harus dimiliki oleh suatu lembaga atau perusahaan apabila ingin mencapai tujuan yang telah ditetapkan. Dalam kegiatannya organisasi atau perusahaan harus mampu meningkatkan kinerja dari waktu ke waktu, karena ini menyangkut terhadap kinerja lembaga tersebut. Kinerja yang baik mampu menunjukkan jumlah pencapaian yang meningkat dan memenuhi kualitas pekerjaan yang baik, mampu melakukan tindakan yang mampu menunjang pekerjaan secara optimal, memiliki kepercayaan diri yang baik dalam menyelesaikan pekerjaan, bertanggung jawab 
sepenuhnya pada tugas dan kewajibannya. Disamping itu karyawan juga memiliki kemampuan dalam mengatasi persoalan dalam pekerjaan sehingga mampu menambah daya saing perusahaan secara baik. Hal tersebut selaras dengan teori Simamora (2017:612) berpendapat "Kinerja merupakan perbandingan antara hasil yang dicapai seseorang dengan target yang ditetapkan dalam waktu tertentu dengan sumber daya yang digunakan" Sedangkan menurut Wibowo (2016:18) mengemukakan "Kinerja merupakan hasil pekerjaan yang mempunyai hubungan kuat strategis organisasi, kepuasan kenosumen dan memberikan kontribusi ekonomi".

Berdasarkan latar belakang permasalahan diatas, maka penulis tertarik untuk melakukan penelitian lebih lanjut dengan judul: "Pengaruh Motivasi dan Disiplin Terhadap Kinerja Karyawan Pada PT. Victory Chingluh Indonesia DiTangerang".

\section{METODE PENELITIAN}

Jenis penelitian ini adalah kuantitatif, menurut Sugiyono (2018:8) penelitian kuantitatif adalah: "Metode penelitian yang berlandaskan pada filsafat positivisme, digunakan untuk meneliti pada populasi atau sampel tertentu, pengumpulan data menggunakan instrument penelitian, analisis data bersifat kuantutatif atau statistik, dengan tujuan untuk menguji hipotesis yang telah ditetapkan". Adapun pendekatan dalam penelitian ini digunakan deskriptif dan verivikatif, Adapun populasi dalam penelitian berjumlah 63 responden PT. Polypet Indonesia di Jakarta, Teknik pengambilan sampling dalam penelitian ini adalah samplel jenuh, dimana semua anggota populasi dijadikan sebagai sampel. Dengan demikian sampel dalam penelitian ini berjumlah 63 responden, Dalam menganalisis data digunakan uji instrument yang terdiri atas (Uji Validitas, dan Uji Reliabilitas), uji asumsi klasik yang terdiri atas (Uji Normalitas, Uji Multikolinieritas, Uji Autokorelasi, dan Uji Heterskedastisitas), Uji Statistik yang terdiri atas (regresi Linear, Koefisien Korelasi, Koefisien Determinasi, dan Uji Hipotesis).

\section{HASIL DAN PEMBAHASAN}

\section{A. Hasil Penelitian}

\section{Uji Intrumen}

Berikut disampaikan beberapa hasil Uji Instrumen yang dilakukan dalam penelitian ini: a) Dari hasil pengujian diperoleh seluruh item kuesioner variabel motivasi diperoleh nilai signifikansi 2 tailed sebesar $0,000<0,05$, dengan demikian instrumen valid.

b) Dari hasil pengujian diperoleh seluruh item kuesioner variabel disiplin diperoleh nilai signifikansi 2 tailed sebesar $0,000<$ 0,05 , dengan demikian instrumen valid.

c) Dari hasil pengujian diperoleh seluruh item kuesioner variabel kinerja karyawan diperoleh nilai signifikansi 2 tailed sebesar $0,000<0,05$, dengan demikian instrumen valid.

d) Dari hasil pengujian reliabilitas, diperoleh hasil sebagai berikut:

Tabel 1. Hasil Pengujian Reliabilitas

\begin{tabular}{lccc}
\hline Variabel & $\begin{array}{c}\text { Cronb } \\
\text { ach's } \\
\text { Alpha }\end{array}$ & $\begin{array}{c}\text { Standar } \\
\text { Kritis } \\
\text { Alpha }\end{array}$ & Keterangan \\
\hline Motivasi (X1) & 0,768 & 0,600 & Reliabel \\
\hline Disiplin (X2) & 0,668 & 0,600 & Reliabel \\
\hline Kinerja Karyawan (Y) & 0,724 & 0,600 & Reliabel \\
\hline
\end{tabular}

Berdasarkan hasil diatas, keseluruhan variabel motivasi (X1), disiplin (X2) diperoleh nilai cronbach alpha lebih besar dari 0,600. Dengan demikian dinyatakan reliabel.

\section{Uji Asumsi Klasik}

a) Uji Normalitas

Hasil uji normalitas dengan alat uji Kolmogorov-Smirnov Test, sebagai berikut:

Tabel 2. Hasil Uji Normalitas KolmogorovSmirnov Test

\begin{tabular}{|c|c|c|c|c|c|c|}
\hline \multicolumn{7}{|c|}{ Tests of Normality } \\
\hline & \multicolumn{3}{|c|}{ Kolmogorov-Smirnov } & \multicolumn{3}{|c|}{ Shapiro-Wilk } \\
\hline & Statistic & $\mathrm{df}$ & Sig. & Statistic & df & Sig. \\
\hline $\begin{array}{l}\text { Kinerja } \\
\text { Karyawan } \\
\text { (Y) }\end{array}$ & .090 & 63 & $.200^{*}$ & .966 & 63 & .083 \\
\hline
\end{tabular}

Berdasarkan hasil pengujian pada tabel diatas diperoleh nilai signifikansi 0,200 dimana nilai tersebut lebih besar dari nilai $\alpha=0,050$ atau $(0,200>0,050)$, dengan demikian maka asumsi distribusi persamaan pada uji ini adalah normal.

b) Uji Multikonilieritas

Uji multikolinearitas dilakukan dengan melihat nilai Tolerance Value dan Variance Inflation Factor (VIF). Adapun hasil pengujiannya sebagai berikut: 
Tabel 3. Hasil Uji Multikolinieritas dengan Collinierity Statistic

\begin{tabular}{|c|c|c|c|c|c|}
\hline \multicolumn{6}{|c|}{ Coefficients } \\
\hline \multirow{2}{*}{ Model } & \multicolumn{2}{|c|}{$\begin{array}{l}\text { Unstandardized } \\
\text { Coefficients }\end{array}$} & \multirow{2}{*}{$\begin{array}{l}\begin{array}{l}\text { Standa } \\
\text { rdized } \\
\text { Coeffici } \\
\text { ents }\end{array} \\
\text { Beta }\end{array}$} & \multicolumn{2}{|c|}{$\begin{array}{l}\text { Collinearity } \\
\text { Statistics }\end{array}$} \\
\hline & B & Std. Error & & $\begin{array}{l}\text { Toler } \\
\text { ance }\end{array}$ & VIF \\
\hline $\begin{array}{ll}\text { (Const } \\
\text { ant) }\end{array}$ & 5.789 & 3.189 & & & \\
\hline $\begin{array}{l}\text { Motiva } \\
\text { si (X1) }\end{array}$ & .368 & .080 & .415 & .740 & 1.351 \\
\hline $\begin{array}{l}\text { Disipli } \\
\mathrm{n}(\mathrm{X} 2)\end{array}$ & .501 & .090 & .501 & .740 & 1.351 \\
\hline
\end{tabular}

Berdasarkan hasil pengujian pada tabel diatas nilai tolerance masing-masing variabel bebas yaitu $0,740<1,0$ dan nilai Variance Inflation Factor (VIF) sebesar $1,351<10$, dengan demikian model regresi ini tidak terjadi multikolinearitas.

c) Uji Autokorelasi

Pengujian dilakukan dengan alat uji Darbin-Watson ( $D W$ test). Adapun hasil pengujiannya sebagai berikut:

Tabel 4. Hasil Uji Autokorelasi

\begin{tabular}{|c|c|c|c|c|c|}
\hline \multicolumn{6}{|c|}{ Model Summaryb } \\
\hline Model & $\mathrm{R}$ & R Square & $\begin{array}{l}\text { Adjusted } \\
\text { R Square }\end{array}$ & $\begin{array}{l}\text { Std. } \\
\text { Error of } \\
\text { the } \\
\text { Estimate }\end{array}$ & $\begin{array}{l}\text { Durbin- } \\
\text { Watson }\end{array}$ \\
\hline 1 & $.797 a$ & .636 & .624 & 2.297 & 2.185 \\
\hline \multicolumn{6}{|c|}{ a. Predictors: (Constant), Disiplin (X2), Motivasi (X1) } \\
\hline \multicolumn{6}{|c|}{ b. Dependent Variable: Kinerja Karyawan (Y) } \\
\hline
\end{tabular}

Hasil pengujian pada tabel diatas diperoleh nilai Durbin-Watson sebesar 2,185 nilai tersebut berada diantara interval 1.550 2.460. Dengan demikian model regresi dinyatakan tidak ada gangguan auto korelasi.

d) d. Uji Heteroskesdastisitas

Hasil pengujian heteroskedastisitas sebagai berikut:

Tabel 5. Hasil Uji Heteroskesdastisitas dengan Glejser Test Model

\begin{tabular}{|c|c|c|c|c|c|c|}
\hline \multicolumn{7}{|c|}{ Coefficients $^{a}$} \\
\hline \multirow{2}{*}{\multicolumn{2}{|c|}{ Model }} & \multicolumn{2}{|c|}{$\begin{array}{l}\text { Unstandardized } \\
\text { Coefficients }\end{array}$} & \multirow{2}{*}{$\begin{array}{l}\begin{array}{l}\text { Standardi } \\
\text { zed } \\
\text { coefficients } \\
\text { Beta }\end{array} \\
\end{array}$} & \multirow[b]{2}{*}{$\mathrm{t}$} & \multirow[b]{2}{*}{ Sig. } \\
\hline & & B & $\begin{array}{l}\text { Std. } \\
\text { Error }\end{array}$ & & & \\
\hline \multirow[t]{2}{*}{1} & (Constant) & -3.128 & 1.961 & & -1.595 & .116 \\
\hline & $\begin{array}{l}\text { Motivasi } \\
\text { (X1) }\end{array}$ & .045 & .049 & .131 & .913 & .365 \\
\hline
\end{tabular}

$\begin{array}{llllll}\begin{array}{l}\text { Disiplin } \\ \text { (X2) }\end{array} & .084 & .056 & .217 & 1.517 & .134\end{array}$

a. Dependent Variable: RES2

Hasil pengujian dengan menggunakan uji glejser diperoleh nilai Sig. > 0,05. Dengan demikian regression model tidak ada gangguan heteroskesdastisitas.

\section{Analisis Deskriptif}

Pada pengujian ini digunakan untuk mengetahui skor minimum dan maksimum, mean score dan standar deviasi dari masingmasing variabel. Adapun hasilnya sebagai berikut:

Tabel 6. Hasil Analisis Descriptive Statistics

\begin{tabular}{ll|lll|l}
\hline \multicolumn{2}{l}{ Descriptive Statistics } \\
\hline & N & $\begin{array}{l}\text { Mini } \\
\text { mum }\end{array}$ & $\begin{array}{l}\text { Maxi } \\
\text { mum }\end{array}$ & Mean & $\begin{array}{l}\text { Std. } \\
\text { Deviation }\end{array}$ \\
\hline Motivasi (X1) & 63 & 29 & 48 & 37.11 & 4.228 \\
\hline Disiplin (X2) & 63 & 29 & 45 & 37.56 & 3.749 \\
\hline $\begin{array}{l}\text { Kinerja } \\
\text { Karyawan (Y) }\end{array}$ & 63 & 32 & 47 & 38.24 & 3.745 \\
\hline $\begin{array}{l}\text { Valid N } \\
\text { (listwise) }\end{array}$ & 63 & & & & \\
\hline
\end{tabular}

Motivasi diperoleh varians minimum sebesar 29 dan varians maximum 48 dengan mean score sebesar 3,711 dengan standar deviasi 4,228 .

Disiplin diperoleh varians minimum sebesar 29 dan varians maximum 45 dengan mean score sebesar 3,756 dengan standar deviasi 3,749 .

Kinerja karyawan diperoleh varians minimum sebesar 32 dan varians maximum 47 dengan mean score sebesar 3,824 dengan standar deviasi 3,745.

\section{Analisis Kuantitatif}

Pada analisis ini dimaksudkan untuk mengetahui pengaruh variabel independen terhadap variabel dependen. Adapun hasil pengujian sebagai berikut:

a) Analisis Regresi Linier Berganda

Hasil Pengujian regresi linier berganda sebagai berikut:

Tabel 7. Hasil Pengujian Regresi Linier Berganda

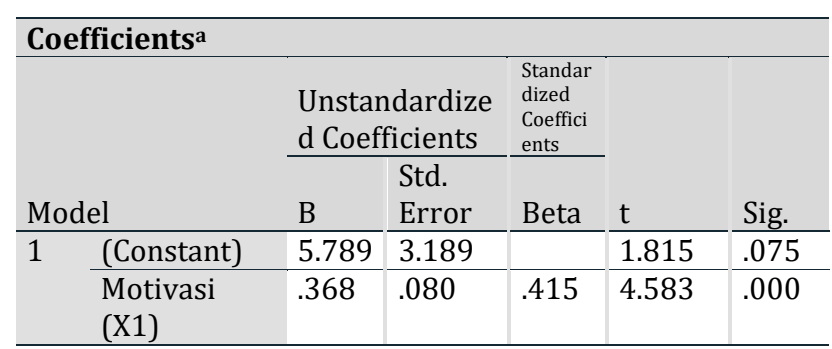


\begin{tabular}{|l|l|l|l|l|l|}
\hline Disiplin (X2) & .501 & .090 & .501 & 5.536 & .000 \\
\hline
\end{tabular}

Berdasarkan hasil pengujian pada tabel di atas, diperoleh persamaan regresi $\mathrm{Y}=$ $5,789+0,368 \mathrm{X} 1+0,501 \mathrm{X} 2 . \quad$ Dari persamaan tersebut dijelaskan sebagai berikut:

1) Konstanta sebesar 5,789 diartikan jika motivasi dan disiplin tidak ada, maka telah terdapat nilai kinerja karyawan sebesar 5,789 point.

2) Koefisien regresi motivasi sebesar 0,368 , angka ini positif artinya setiap ada peningkatan motivasi sebesar 0,368 maka kinerja karyawan juga akan mengalami peningkatan sebesar 0,368 point.

3) Koefisien regresi disiplin sebesar 0,501, angka ini positif artinya setiap ada peningkatan disiplin sebesar 0,501 maka kinerja karyawan juga akan mengalami peningkatan sebesar 0,501 point.

b) Analisis Koefisien Korelasi

Hasil pengujian koefisien korelasi sebagai berikut:

Tabel 8. Hasil Pengujian Koefisien Korelasi Motivasi Terhadap Kinerja Karyawan.

\begin{tabular}{|c|c|c|c|}
\hline \multicolumn{4}{|l|}{ Correlations $^{b}$} \\
\hline & & & Kinerja \\
\hline & & $\begin{array}{l}\text { Motiva } \\
\text { si (X1) }\end{array}$ & $\begin{array}{l}\text { Karyawa } \\
\mathrm{n}(\mathrm{Y})\end{array}$ \\
\hline \multirow[t]{2}{*}{ Motivasi (X1) } & Pearson Correlation & 1 & $.671^{* *}$ \\
\hline & Sig. (2-tailed) & & .000 \\
\hline \multirow{2}{*}{$\begin{array}{l}\text { Kinerja } \\
\text { Karyawan (Y) }\end{array}$} & Pearson Correlation & $.671^{* *}$ & 1 \\
\hline & Sig. (2-tailed) & .000 & \\
\hline
\end{tabular}

Berdasarkan hasil pengujian diperoleh nilai korelasi sebesar 0,671 artinya motivasi memiliki hubungan yang kuat terhadap kinerja karyawan.

Tabel 9. Hasil Pengujian Koefisien Korelasi Disiplin Terhadap Kinerja Karyawan.

\begin{tabular}{llll}
\hline Correlations $^{\mathbf{b}}$ & & & \\
\hline & & $\begin{array}{l}\text { Disiplin } \\
(\mathrm{X} 2)\end{array}$ & $\begin{array}{l}\text { Kinerja } \\
\text { Karyawan } \\
(\mathrm{Y})\end{array}$ \\
\hline Disiplin (X2) & Pearson Correlation & 1 & $.713^{* *}$ \\
\cline { 2 - 3 } & Sig. (2-tailed) & & .000 \\
\hline Kinerja & Pearson Correlation & $.713^{* *}$ & 1 \\
\cline { 2 - 3 } $\begin{array}{l}\text { Karyawan } \\
\text { (Y) }\end{array}$ & Sig. (2-tailed) & .000 & \\
\hline
\end{tabular}

Berdasarkan hasil pengujian diperoleh nilai korelasi sebesar 0,713 artinya disiplin memiliki hubungan yang kuat terhadap kinerja karyawan.
Tabel 10. Hasil Pengujian Koefisien Korelasi

Motivasi dan Disiplin secara simultan Terhadap Kinerja Karyawan.

\begin{tabular}{|c|c|c|c|c|}
\hline \multicolumn{5}{|c|}{ Model Summary } \\
\hline Model & $\mathrm{R}$ & $\begin{array}{l}\mathrm{R} \\
\text { Square }\end{array}$ & $\begin{array}{l}\text { Adjusted } \\
\text { R Square }\end{array}$ & $\begin{array}{l}\text { Std. Error of the } \\
\text { Estimate }\end{array}$ \\
\hline 1 & $.797 a$ & .636 & .624 & 2.297 \\
\hline
\end{tabular}

Berdasarkan hasil pengujian diperoleh nilai korelasi sebesar 0,797 artinya motivasi dan disiplin secara simultan memiliki hubungan yang kuat terhadap kinerja karyawan.

c) Analisis Koefisien Determinasi

Hasil pengujian koefisien determinasi sebagai berikut:

Tabel 11. Hasil Pengujian Koefisien Determinasi Motivasi Terhadap Kinerja Karyawan.

\begin{tabular}{lllll}
\hline \multicolumn{2}{l}{ Model Summary } & & \\
\hline & & & Adjusted R & Std. Error of the \\
Model & R & R Square & Square & Estimate \\
\hline 1 & $.671^{\text {a }}$ & .450 & .441 & 2.800 \\
\hline a. Predictors: (Constant), Motivasi (X1) \\
\hline
\end{tabular}

Berdasarkan hasil pengujian diperoleh nilai determinasi sebesar 0,450 artinya motivasi memiliki kontribusi pengaruh sebesar 45,0\% terhadap kinerja karyawan.

Tabel 12. Hasil Pengujian Koefisien Determinasi Disiplin Terhadap Kinerja Karyawan.

\begin{tabular}{|c|c|c|c|c|}
\hline \multicolumn{5}{|c|}{ Model Summary } \\
\hline Model & $\mathrm{R}$ & R Square & $\begin{array}{l}\text { Adjusted } \\
\text { R Square }\end{array}$ & $\begin{array}{l}\text { Std. Error of the } \\
\text { Estimate }\end{array}$ \\
\hline 1 & $.713^{a}$ & .508 & .500 & 2.647 \\
\hline \multicolumn{5}{|c|}{ a. Predictors: (Constant), Disiplin (X2) } \\
\hline
\end{tabular}

Berdasarkan hasil pengujian diperoleh nilai determinasi sebesar 0,508 artinya disiplin memiliki kontribusi pengaruh sebesar 50,8\% terhadap kinerja karyawan.

Tabel 13. Hasil Pengujian Koefisien Determinasi Motivasi dan Disiplin Terhadap Kinerja Karyawan.

\begin{tabular}{llllll}
\hline Model Summary & & & \\
& & $\mathrm{R}$ & & \\
& & Squa & Adjusted & Std. Error of the \\
Model & $\mathrm{R}$ & re & R Square & Estimate \\
\hline 1 & .797 a & .636 & .624 & 2.297 \\
\hline
\end{tabular}

a. Predictors: (Constant), Disiplin (X2), Motivasi (X1)

Berdasarkan hasil pengujian diperoleh nilai determinasi sebesar 0,636 artinya motivasi dan disiplin secara simultan memiliki kontribusi pengaruh sebesar $63,6 \%$ terhadap kinerja karyawan, 
sedangkan sisanya sebesar $36,4 \%$ dipengaruhi faktor lain.

\section{d) Uji Hipotesis}

\section{Uji hipotesis Parsial (Uji t)}

Pengujian hipotesis dengan uji t digunakan untuk mengetahui hipotesis parsial mana yang diterima.

Hipotesis pertama: Terdapat pengaruh yang signifikan motivasi terhadap kinerja karyawan.

Hipotesis kedua: Terdapat pengaruh yang signifikan disiplin terhadap kinerja karyawan.

Tabel 14. Hasil Uji Hipotesis Motivasi Terhadap Kinerja Karyawan.

\begin{tabular}{|c|c|c|c|c|c|}
\hline \multicolumn{6}{|l|}{ Coefficients $^{\mathbf{a}}$} \\
\hline \multirow[b]{2}{*}{ Model } & \multicolumn{2}{|c|}{$\begin{array}{l}\text { Unstandardized } \\
\text { Coefficients }\end{array}$} & \multirow{2}{*}{$\begin{array}{l}\begin{array}{l}\text { Standa } \\
\text { rdized } \\
\text { Coeffici } \\
\text { ents }\end{array} \\
\text { Beta }\end{array}$} & \multirow[b]{2}{*}{$\mathrm{t}$} & \multirow[b]{2}{*}{ Sig. } \\
\hline & B & $\begin{array}{l}\text { Std. } \\
\text { Error }\end{array}$ & & & \\
\hline 1 (Constant) & 16.192 & 3.142 & & 5.154 & .000 \\
\hline $\begin{array}{l}\text { Motivasi } \\
\text { (X1) }\end{array}$ & .594 & .084 & .671 & 7.062 & .000 \\
\hline
\end{tabular}

Berdasarkan hasil pengujian pada tabel di atas, diperoleh nilai $t$ hitung $>t$ tabel atau $(7,062>2,000)$, dengan demikian hipotesis pertama yang diajukan bahwa terdapat pengaruh yang signifikan atara motivasi terhadap kinerja karyawan diterima.

Tabel 15. Hasil Uji Hipotesis Disiplin

Terhadap Kinerja Karyawan.

\begin{tabular}{|c|c|c|c|c|c|}
\hline \multicolumn{6}{|l|}{ Coefficients $^{a}$} \\
\hline \multirow[b]{2}{*}{ Model } & \multicolumn{2}{|c|}{$\begin{array}{l}\text { Unstandardized } \\
\text { Coefficients }\end{array}$} & \multirow{2}{*}{$\begin{array}{l}\begin{array}{l}\text { Standa } \\
\text { rdized } \\
\text { Coeffici } \\
\text { ents }\end{array} \\
\text { Beta }\end{array}$} & \multirow[b]{2}{*}{$\mathrm{t}$} & \multirow[b]{2}{*}{ Sig. } \\
\hline & B & $\begin{array}{l}\text { Std. } \\
\text { Error }\end{array}$ & & & \\
\hline 1 (Constant) & 11.493 & 3.384 & & 3.397 & .001 \\
\hline $\begin{array}{l}\text { Disiplin } \\
\text { (X2) }\end{array}$ & .712 & .090 & .713 & 7.942 & .000 \\
\hline
\end{tabular}

Berdasarkan hasil pengujian pada tabel di atas, diperoleh nilai $\mathrm{t}$ hitung $>\mathrm{t}$ tabel atau $(7,942>2,000)$, dengan demikian hipotesis kedua yang diajukan bahwa terdapat pengaruh yang signifikan atara disiplin terhadap kinerja karyawan diterima.

\section{Uji Hipotesis Simultan (Uji F)}

Pengujian hipotesis dengan uji F digunakan untuk mengetahui hipotesis simultan yang mana yang diterima.
Hipotesis ketiga Terdapat pengaruh yang signifikan antara motivasi dan disiplin terhadap kinerja karyawan.

Tabel 16. Hasil Uji Hipotesis Motivasi dan Disiplin Terhadap Kinerja Karyawan.

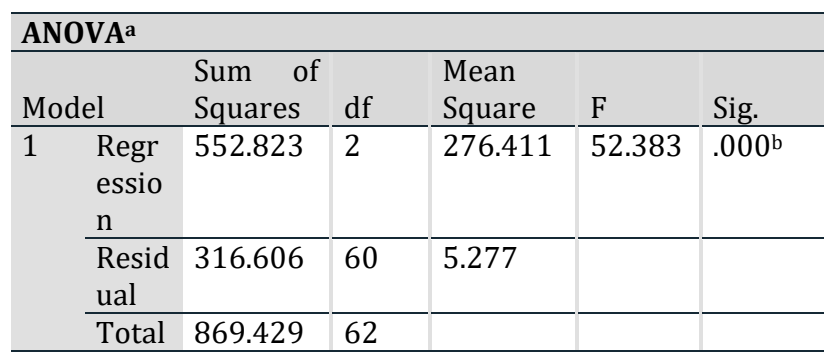

Berdasarkan hasil pengujian pada tabel di atas, diperoleh nilai $\mathrm{F}$ hitung $>\mathrm{F}$ tabel atau $(18,770>2,760)$, dengan demikian hipotesis ketiga yang diajukan bahwa terdapat pengaruh yang signifikan atara motivasi dan disiplin terhadap kinerja karyawan diterima.

\section{B. Pembahasan}

Beberapa penyampaian pembahasan setelah dilakukan beberapa analisis hasil.

1) Pengaruh Motivasi Terhadap Kinerja Karyawan

Dari hasil analisis diperoleh variabel motivasi berpengaruh signifikan terhadap kinerja karyawan dengan nilai korelasi sebesar 0,671 artinya kedua variabel memiliki hubungan yang kuat dengan kontribusi pengaruh sebesar 45,0\%. Pengujian hipotesis diperoleh nilai $t$ hitung $>\mathrm{t}$ tabel atau $(7,062>2,000)$. Dengan demikian hipotesis pertama yang diajukan bahwa terdapat berpengaruh signifikan antara motivasi terhadap kinerja karyawan diterima.

2) Pengaruh Disiplin Terhadap Kinerja Karyawan

Dari hasil analisis diperoleh variabel disiplin berpengaruh signifikan terhadap kinerja karyawan dengan nilai korelasi sebesar 0,713 artinya kedua variabel memiliki hubungan yang kuat dengan kontribusi pengaruh sebesar 50,8\%. Pengujian hipotesis diperoleh nilai $\mathrm{t}$ hitung $>\mathrm{t}$ tabel atau $(7,942>2,000)$. Dengan demikian hipotesis kedua yang diajukan bahwa terdapat berpengaruh signifikan antara disiplin terhadap kinerja karyawan diterima.

3) Pengaruh Motivasi dan Disiplin Terhadap Kinerja Karyawan

Dari hasil analisis diperoleh variabel motivasi dan disiplin berpengaruh signifikan terhadap 
kinerja karyawan dengan diperoleh persamaan regresi $\mathrm{Y}=5,789+0,368 \mathrm{X} 1+$ 0,501X2, nilai korelasi sebesar 0,797 artinya kedua variabel memiliki hubungan yang kuat dengan kontribusi pengaruh sebesar 63,6\% sedangkan sisanya sebesar 36,4\% dipengaruhi faktor lain. Pengujian hipotesis diperoleh nilai $\mathrm{F}$ hitung $>\mathrm{F}$ tabel atau $(18,770$ $>2,760$ ). Dengan demikian hipotesis ketiga yang diajukan bahwa terdapat berpengaruh signifikan antara motivasi dan disiplin terhadap kinerja karyawan diterima.

\section{SIMPULAN DAN SARAN}

\section{A. Simpulan}

Beberapa kesimpulan yang dapat diuraikan setelah melihat hasil penelitian dan pembahasan yaitu:

1) Motivasi berpengaruh signifikan terhadap kinerja karyawan nilai korelasi sebesar 0,671 atau kuat dengan kontribusi pengaruh sebesar $45,0 \%$. Uji hipotesis diperoleh nilai t hitung $>\mathrm{t}$ tabel atau $(7,062>2,000)$. Dengan demikian terdapat pengaruh yang signifikan antara motivasi terhadap kinerja karyawan pada PT. Polypet Indonesia di Jakarta.

2) Disiplin berpengaruh signifikan terhadap kinerja karyawan dengan nilai korelasi sebesar 0,713 atau kuat dengan kontribusi pengaruh sebesar 50,8\%. Uji hipotesis diperoleh nilai thitung $>\mathrm{t}$ tabel atau $(7,942>$ 2,000). Dengan demikian terdapat pengaruh yang signifikan antara disiplin terhadap kinerja karyawan pada PT. Polypet Indonesia di Jakarta.

3) Motivasi dan disiplin berpengaruh signifikan terhadap kinerja karyawan dengan nilai korelasi sebesar 0,797 atau kuat dengan kontribusi pengaruh sebesar 63,6\% sedangkan sisanya sebesar $36,4 \%$ dipengaruhi faktor lain. Uji hipotesis diperoleh nilai $\mathrm{F}$ hitung $>\mathrm{F}$ tabel atau $(18,770$ $>2,760$ ). Dengan demikian terdapat pengaruh yang signifikan antara motivasi dan disiplin secara simultan terhadap kinerja karyawan pada PT. Polypet Indonesia di Jakarta.

\section{B. Saran}

Berikut disampaikan saran yang dapat dijadikan rujukan dalam perbaikan kondisi lokasi penelitian maupun penelitian ini sendiri:

1) ketentuan yang berlaku guna menjamin karyawan diperlakukan dengan adil.

2) Perusahaan harus selalu memberikan semangat dan apresiasi yang layak untuk memastikan karyawan memiliki semangat kerja yang tinggi.

3) Kinerja perusahaan dapat ditingkatkan dengan memberdayakan karyawan dengan menegakkan peraturan yang baik dan pemberian disiplin yang lebih inten lagi.

\section{DAFTAR RUJUKAN}

Algifari. (2015). “Analisis Regresi untuk Bisnis dan Ekonomi”. Yogyakarta: BPFE.

Arikunto, Suharsimi (2014). "Prosedur Penelitian Suatu Pendekatan Praktek”. Jakarta: Rineka Cipta.

Edi Sutrisno (2016). Manajemen Sumber Daya Manusia. Jakarta: Prenadamedia Group.

Freed Luthans (2016) Organizational Behavior, McGraw-Hill, New York.

Gerry Dessler (2016) Human Resources Management, Prenticehall, London: International Inc.

Handoko (2016) Manajemen Personalia dan Sumberdaya Manusia. Yogyakarta: BPFE.

Hasibuan (2016) "Manajemen Sumber Daya Manusia". Haji Masagung. Jakarta.

Henry Simamora (2005), Manajemen Sumber Daya Manusia, STIE YKPN Bandung.

Imam Ghozali (2017). “Aplikasi Analisis Multivariate Dengan Program SPSS". Edisi Kelima. Semarang: Badan Penerbit Undip.

Mangkunegara, Prabu Anwar. (2016). Evaluasi Kinerja SDM. Cetakan ke tujuh, PT Refika Aditama: Bandung.

Nitisemito, Alek.S, (2010), Manajemen Personalia, Ghalia Indonesia, Jakarta.

Rivai Veithzal (2015) Manajemen Sumber Daya Manusia Untuk Perusahaan. Jakarta: PT Raja Grafindo Persada.

Rivai Veithzal (2015) Manajemen Sumber Daya Manusia Untuk Perusahaan. Penerbit PT Raja Grafindo Persada, Jakarta, 2010.

Santoso, Singgih (2015). "Menguasai Statistik Multivariat". Jakarta: PT Elex Media Komputindo.

Siagian, S (2007). Manajemen Sumber Daya Manusia. Jakarta: Bumi Aksara. Sinamo, J. 
JIIP-Jurnal Ilmiah Ilmu Pendidikan (2614-8854) Volume 4, Nomor 5, September 2021 (360-367)

(2011). Delapan Etos

Profesional. Jakarta: Institut
Kerja

Sugiyon

Metode Penelitian Administrasi : dilengkapi dengan Metode $R \& D "$ Bandung: Alfabeta. 